\title{
Optimizing mean arterial pressure in septic shock: a critical reappraisal of the literature
}

\author{
Marc Leone ${ }^{1 *}$, Pierre Asfar ${ }^{2}$, Peter Radermacher ${ }^{3}$, Jean-Louis Vincent ${ }^{4}$ and Claude Martin ${ }^{1}$
}

\begin{abstract}
Guidelines recommend that a mean arterial pressure (MAP) value greater than $65 \mathrm{~mm} \mathrm{Hg}$ should be the initial blood pressure target in septic shock, but what evidence is there to support this statement? We searched Pubmed and Google Scholar by using the key words 'arterial pressure', 'septic shock', and 'norepinephrine' and retrieved human studies published between 1 January 2000 and 31 July 2014. We identified seven comparative studies: two randomized clinical trials and five observational studies. The results of the literature review suggest that a MAP target of $65 \mathrm{~mm} \mathrm{Hg}$ is usually sufficient in patients with septic shock. However, a MAP of around 75 to $85 \mathrm{~mm} \mathrm{Hg}$ may reduce the development of acute kidney injury in patients with chronic arterial hypertension. Because of the high prevalence of chronic arterial hypertension in patients who develop septic shock, this finding is of considerable importance. Future studies should assess interactions between time, fluid volumes administered, and doses of vasopressors.
\end{abstract}

\section{Introduction}

The blood pressure value that should be targeted during the management of septic shock is an important clinical issue. The mean arterial pressure (MAP) is one of the first variables that is monitored in these patients, and manipulation with vasopressor agents is relatively easy. Prolonged hypotension, defined as a MAP of less than 60 to $65 \mathrm{~mm} \mathrm{Hg}$, is associated with poor outcome [1,2].

The Surviving Sepsis Guidelines recommend that vasopressor therapy initially target a MAP of $65 \mathrm{~mm} \mathrm{Hg}$ (grade $1 \mathrm{C}$ recommendation) [3] but that the actual value be individualized because the optimal MAP may be higher in

\footnotetext{
* Correspondence: marc.leone@ap-hm.fr

'Service d'Anesthésie et de Réanimation, Chemin des Bourrely, Hôpital Nord, Assistance Publique-Hôpitaux de Marseille, Aix Marseille Université, 13015 Marseille, France

Full list of author information is available at the end of the article
}

older patients with atherosclerosis or previous hypertension (or both) than in younger patients without cardiovascular comorbidity [3]. After the initial resuscitation period, the ideal MAP target remains a matter of debate. In addition, a randomized clinical trial that tested the effects of norepinephrine versus a nitric oxide inhibitor in patients with septic shock suggested that an abrupt and sustained increase in MAP could be detrimental and was associated with an increased mortality rate [4]. However, it remains unclear whether the increased mortality was due to the adverse effect of the drug itself or to the excessive level of arterial pressure per se. We reviewed the published data related to MAP targets in septic shock and discuss the clinical implications.

\section{Overview of relationship between arterial pressure and organ perfusion}

Septic shock is characterized by both vasodilation and cardiac dysfunction, leading to a decrease in blood pressure. Hypotension generates organ failure due to hypoperfusion, with the MAP reflecting the driving pressure at the organ level. The goal of resuscitation is to restore adequate organ perfusion (that is, to optimize the relationship between oxygen needs and oxygen supply). In healthy individuals, blood flow remains constant over a large range of blood pressures, at least in the brain and the kidney. For many years, researchers have hypothesized that this autoregulatory mechanism is impaired in septic shock [5-7], so that increasing blood pressure will increase organ blood flow (Figure 1). In addition, the autoregulation threshold is dependent on the basal level of blood pressure, tending to be higher in patients with than in those without a prior history of arterial hypertension (Figure 1) [8]. The 'optimal' MAP target, therefore, may differ according to the patient's medical history. Moreover, there are many autoregulatory thresholds depending on the specific tissue. In general, our goal is to provide an adequate perfusion to vital organs, which tend to have higher thresholds than less critical organs, such as skeletal muscle [9]. 


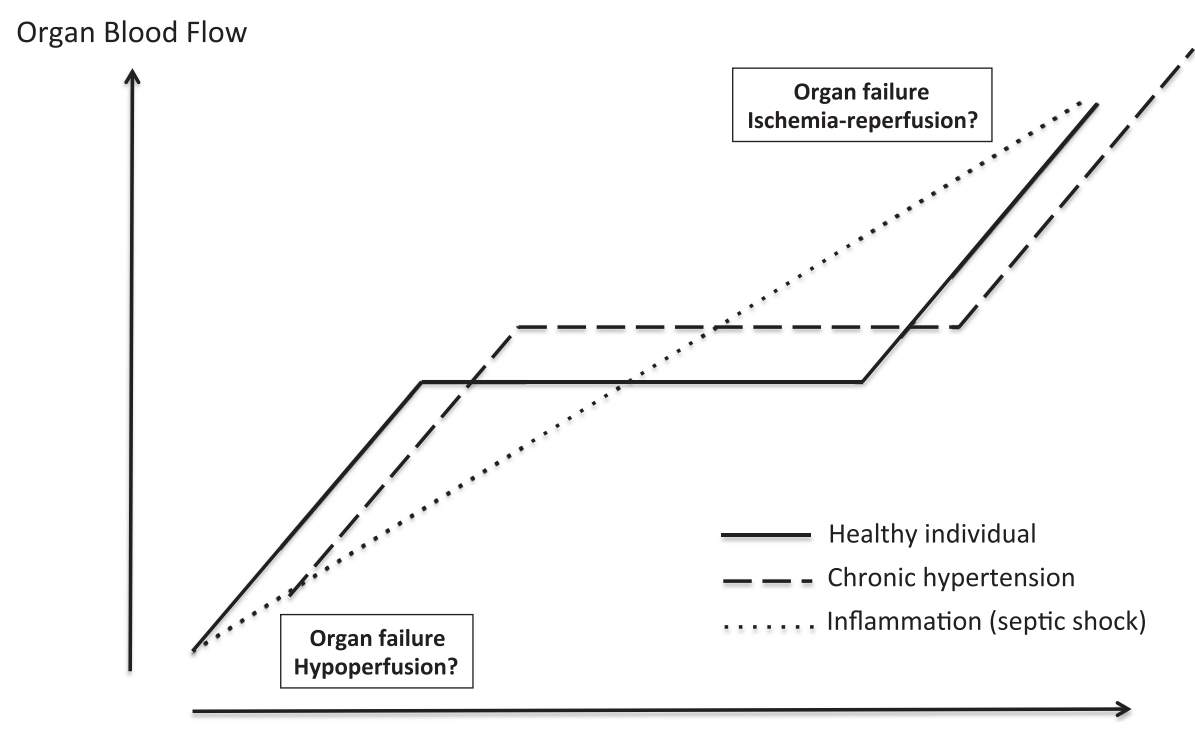

Blood pressure

Figure 1 Organ blood flow and blood pressure relationships in healthy individuals, individuals with chronic hypertension, and patients with septic shock. The third linear relationship is theoretical.

The microcirculation is markedly altered in septic shock $[10,11]$. Altered circulating cells, disseminated intravascular coagulation, peripheral edema, and impaired mitochondrial function have been implicated [12]. Interestingly, the microcirculation can still be impaired when the blood pressure goals of resuscitation, as recommended by guidelines [3], have been reached [13,14], suggesting that these hemodynamic goals may be inadequate for some patients (that is, not high enough) and that increasing blood pressure to higher levels may be warranted in some patients. On the other hand, these observations may imply that the microcirculation is at least partially independent of systemic hemodynamics, so that a further increase in arterial pressure may not improve microcirculatory blood flow or may even threaten it.

These concepts are based on the theoretically linear relationship between pressure and flow in septic states (Figure 1). To reach a high blood pressure target value, supplemental fluid volume and increasing dosages of inotropes or vasopressors or both are required. These drugs have adverse effects that are associated with organ failure [15], particularly true for catecholamines, the most common drugs used to maintain or increase blood pressure.

Experimentally, increasing arterial pressure excessively has harmful effects. In an ovine model of septic shock, Corrêa and colleagues [16] showed that targeting a MAP of between 50 and $60 \mathrm{~mm} \mathrm{Hg}$ was associated with an increased incidence of acute kidney injury (AKI). In critically ill patients, unfavorable outcomes have been reported with persistent MAP values of less than 60 to
$65 \mathrm{~mm} \mathrm{Hg}$ [1,2]. Also, although MAP levels of $54 \mathrm{~mm} \mathrm{Hg}$ have been associated with worse microcirculatory variables, increasing MAP to more than $65 \mathrm{~mm} \mathrm{Hg}$ was associated with improved microcirculatory parameters [17]. Overall, data suggest that a level of MAP at $65 \mathrm{~mm} \mathrm{Hg}$ is probably the minimal goal that should be targeted in septic shock. However, targeting a higher MAP (75 to $85 \mathrm{~mm}$ $\mathrm{Hg}$ ) during resuscitation of otherwise healthy swine with fecal peritonitis-induced septic shock did not ameliorate the inflammatory response and resulted in increased net positive fluid balance and vasopressor load during resuscitation [16]. Hence, a MAP target that is too low may be associated with organ hypoperfusion, whereas one that is too high may be associated with ischemic injury due to excessive vasoconstriction.

\section{Literature review}

\section{Methods}

Pubmed and Google Scholar were searched by using the key words 'arterial pressure,' 'septic shock', and 'norepinephrine'. The search was limited to studies published between 1 January 2000 and 31 July 2014. Only randomized clinical trials, comparative studies, and observational studies were analyzed; reviews and editorials were excluded as were animal studies and studies published in languages other than English.

\section{Results}

We identified 12 studies; seven were comparative studies determining the effect of different goals of blood pressure on outcome (Table 1) [18-24], and five were observational 
Table 1 Studies comparing different levels of mean arterial pressure in septic shock

\begin{tabular}{|c|c|c|c|c|c|c|}
\hline Reference & Study design & $\begin{array}{l}\text { Number of } \\
\text { patients }\end{array}$ & $\begin{array}{l}\text { Targeted MAP, } \\
\mathrm{mm} \mathrm{Hg}\end{array}$ & Primary outcomes & $\begin{array}{l}\text { Severity } \\
\text { score }\end{array}$ & $\begin{array}{l}\text { 28-day } \\
\text { mortality, \% }\end{array}$ \\
\hline LeDoux et al. [18] (2000) & Prospective cohort & 10 & $65,75,85$ & $\begin{array}{l}\text { Regional circulation and } \\
\text { oxygen metabolism }\end{array}$ & APACHE II: 29 & 70 \\
\hline Bourgoin et al. [19] (2005) & Randomized clinical trial & 28 & 65,85 & $\begin{array}{l}\text { Regional circulation and } \\
\text { oxygen metabolism }\end{array}$ & APACHE II: 27 & NA \\
\hline Deruddre et al. [20] (2007) & Prospective cohort & 11 & $65,75,85$ & Renal perfusion & SAPS II: 57 & NA \\
\hline Jhanji et al. [21] (2009) & Prospective cohort & 16 & $60,70,80,90$ & Microcirculation & APACHE II: 23 & 62.5 \\
\hline Thooft et al. [22] (2011) & Prospective cohort & 13 & $65,75,85,65$ & Microcirculation & APACHE II: 23 & 17 \\
\hline Dubin et al. [23] (2009) & Prospective cohort & 20 & $65,75,85$ & Microcirculation & APACHE II: 24 & 50 \\
\hline Asfar et al. [24] (2014) & Randomized clinical trial & 776 & 65,85 & 28-day mortality & SAPS II: 57 & 35 \\
\hline
\end{tabular}

APACHE II, Acute Physiology and Chronic Health Evaluation II; MAP, mean arterial pressure; NA, not available; SAPS II, Simplified Acute Physiology Score II.

studies (Table 2) analyzing hemodynamic variables in patients with septic shock to determine the influence of arterial pressure on outcomes [1,2,25-27]. The end-points were mortality, regional circulation, and microcirculation in four [1,2,24,25], five [18-20,26,27], and three [21-23] studies, respectively. Among the seven comparative studies, six studies included fewer than 30 patients [18-23]; one of the two randomized clinical trials included 776 patients [24]. Because of the relative weight of this latter study, it will likely have a larger impact on future guidelines than the smaller studies. Nevertheless, the smaller studies collected useful additional informative data that were not included in the large study. Surprisingly, severity scores were similar in the different studies, although mortality rates were highly variable, ranging from $17 \%$ to $76 \%$.

\section{Mean arterial pressure and macro-hemodynamics}

MAP was increased from 65 to $85 \mathrm{~mm} \mathrm{Hg}$ in six of the comparative studies [18-20,22-24] and to 60, 70, 80, and $90 \mathrm{~mm} \mathrm{Hg}$ in one study [21]. Overall in the studies, the increase in MAP was achieved by a $1.7 \pm 0.4 \mu \mathrm{g} / \mathrm{kg}$ per minute increase in norepinephrine infusion. Heart rate was not affected by the increase in norepinephrine infusion, but cardiac output increased. Because the increase in MAP was greater than the increase in cardiac output, systemic vascular resistance increased (Table 3). Mean pulmonary arterial pressure changed inconsistently.

\section{Effects on organ function}

The effects on organ function of increasing MAP from 65 to $85 \mathrm{~mm} \mathrm{Hg}$ were assessed in two comparative studies $[18,19]$, which included a total of 38 patients. The first study included 10 patients in whom MAP was progressively increased to three levels $(65,75$, and $85 \mathrm{~mm}$ $\mathrm{Hg}$ ) [18]. In the second study, variables were measured at a MAP of $65 \mathrm{~mm} \mathrm{Hg}$ and then the MAP was either kept at $65 \mathrm{~mm} \mathrm{Hg}$ or increased to $85 \mathrm{~mm} \mathrm{Hg}$ [19]. The findings were consistent in the two studies and showed no differences in gastric or renal circulations with the different MAP targets. In the three observational studies that assessed the effect of different MAPs on organ function, a MAP of less than $75 \mathrm{~mm} \mathrm{Hg}$ was associated with development of AKI $[1,26,27]$.

Deruddre and colleagues [20] prospectively studied the relationship between MAP and organ function, increasing the MAP from 65 to 75 and $85 \mathrm{~mm} \mathrm{Hg}$ by increasing the norepinephrine infusion rate in 11 patients with septic shock. The renal resistive index measured by pulsed Doppler in the interlobar renal arteries decreased and urine output increased when MAP was increased from

Table 2 Observational studies assessing the effect of mean arterial pressure on outcomes

\begin{tabular}{|c|c|c|c|c|c|c|}
\hline Reference & Type of study & $\begin{array}{l}\text { Number of } \\
\text { patients }\end{array}$ & Primary outcomes & $\mathrm{MAP}, \mathrm{mm} \mathrm{Hg}$ & Severity score & 28-day mortality, \% \\
\hline Varpula et al. [1] (2005) & $\begin{array}{l}\text { Retrospective } \\
\text { cohort }\end{array}$ & 111 & 30-day mortality & 65 & APACHE ॥: 17 & 33.3 \\
\hline Dünser et al. [2] (2009) & $\begin{array}{l}\text { Retrospective } \\
\text { cohort }\end{array}$ & 274 & 28-day mortality & $>60$ & $\begin{array}{l}\text { SAPS: } 52 \text { APACHE } \\
\text { I: } 27\end{array}$ & 27.7 \\
\hline Dünser et al. [25] (2009) & Post hoc analysis & 290 & 28-day mortality & $>70$ & SAPS ॥: 58 & 76 \\
\hline Badin et al. [26] (2011) & Prospective cohort & 217 & $\begin{array}{l}\text { Acute kidney injury } \\
\text { at } 72 \text { hours }\end{array}$ & $72-82$ & SAPS II: 53 & $39^{a}$ \\
\hline Poukkanen et al. [27] (2013) & Prospective cohort & 423 & $\begin{array}{l}\text { Acute kidney injury } \\
\text { at day } 5\end{array}$ & 73 & SAPS ॥: 40 & $24^{\mathrm{a}}$ \\
\hline
\end{tabular}


Table 3 Hemodynamic variables for mean arterial pressure targets of 65 and 85 mm $\mathbf{~ H g}$

\begin{tabular}{|c|c|c|c|c|}
\hline Variables & References & Number of patients & $65 \mathrm{~mm} \mathrm{Hg}^{\mathrm{a}}$ & $85 \mathrm{~mm} \mathrm{Hg}^{\mathrm{a}}$ \\
\hline Heart rate, beats per min & [16-22] & 874 & $100 \pm 11$ & $101 \pm 11$ \\
\hline Cardiac index, $\mathrm{L} / \mathrm{min}$ per $\mathrm{m}^{2}$ & {$[16-21]$} & 98 & $3.9 \pm 1.9$ & $4.3 \pm 1.2$ \\
\hline $\mathrm{SvO}_{2}$ or $\mathrm{ScvO}_{2}, \%$ & {$[16,17,19-21]$} & 87 & $74 \pm 2$ & $75 \pm 3$ \\
\hline Lactate, $\mathrm{mmol} / \mathrm{L}$ & {$[16-21]$} & 98 & $2.3 \pm 0.3$ & $2.2 \pm 0.4$ \\
\hline Norepinephrine, $\mu \mathrm{g} / \mathrm{kg}$ per min & {$[16-21]$} & 874 & $0.47 \pm 0.38$ & $0.79 \pm 0.52$ \\
\hline
\end{tabular}

${ }^{\mathrm{a}}$ With respect to reference [19], values were derived from the calculation of mean values between $60 \mathrm{and} 70 \mathrm{~mm} \mathrm{Hg}$ for $65 \mathrm{~mm} \mathrm{Hg}$ and between 80 and $90 \mathrm{~mm}$ $\mathrm{Hg}$ for $85 \mathrm{~mm} \mathrm{Hg}$. MAP, mean arterial pressure; $\mathrm{ScvO}_{2}$, central venous oxygen saturation; $\mathrm{SvO}_{2}$, mixed venous oxygen saturation.

65 to $75 \mathrm{~mm} \mathrm{Hg}$ but not when MAP was increased from 75 to $85 \mathrm{~mm} \mathrm{Hg}$. Creatinine clearance was unaffected.

The effects of mean arterial pressure on oxygen metabolism Oxygen exchange was measured in five of the comparative studies $[18,19,21-23]$. Increase in cardiac output was associated with an increase in oxygen delivery; whole body oxygen uptake did not change. Plasma lactate levels were unaffected. The effects of increasing MAP on mixed venous oxygen saturation or central venous oxygen saturation were inconsistent: mixed venous oxygen saturation/ central venous oxygen saturation increased in three studies $[18,20,21]$ and was unchanged in two studies $[18,23]$. This discrepancy may be due to several factors, including the preload of patients and their cardiac function. The magnitude of change in oxygen variables did not appear to be clinically relevant (Table 3 ).

\section{Effects on the microcirculation}

The effects of an increase in MAP on the microcirculation were variable. Using sidestream darkfield (SDF) imaging, Dubin and colleagues [23] increased MAP to 65,75 , and $85 \mathrm{~mm} \mathrm{Hg}$ and measured sublingual capillary microvascular flow index or the proportion of perfused capillaries. In patients with septic shock, increasing MAP improved microcirculatory variables in the patients with impaired microcirculation at baseline. In contrast, the microcirculation was impaired when baseline conditions were normal. This underlines the need for an individualized assessment. Using near-infrared spectroscopy with vaso-occlusive tests, Thooft and colleagues [22] found that perfusion was slightly improved when MAP was increased from 75 to $85 \mathrm{~mm} \mathrm{Hg}$ but that it was impaired when MAP was decreased to $65 \mathrm{~mm} \mathrm{Hg}$. However, these effects were quite variable from one patient to another. In a study using measurement of intra-cutaneous oxygen partial pressure via a Clark electrode coupled with laser Doppler flowmetry, Jhanji and colleagues [21] found that increase in MAP was accompanied by a significant increase in cutaneous oxygen partial pressure and red blood cell flow, whereas the sublingual microcirculation explored by SDF imaging was unaffected.

\section{Effects on mortality}

In two of the observational studies, MAP levels of less than 60 to $70 \mathrm{~mm} \mathrm{Hg}$ were independent determinants of mortality $[1,2]$. However, in a post hoc analysis, Dünser and colleagues [25] found no association between MAP and mortality.

In a large randomized clinical trial of 776 patients, Asfar and colleagues [24] compared the effects of lowtarget and high-target MAP on mortality. The study was designed to show an absolute $10 \%$ difference in mortality at day 28 , assuming a mortality rate of $45 \%$. The patients were allocated to protocols targeting MAPs of 65 to $70 \mathrm{~mm} \mathrm{Hg}$ or 80 to $85 \mathrm{~mm} \mathrm{Hg}$ for 5 days. As expected, the doses of norepinephrine were higher in the highMAP target group than in the low-target group, but the cumulative fluid balance was similar. The 28-day mortality rate was $35 \%$ in both groups. The only difference was a higher rate of de novo atrial fibrillation in the hightarget group (6.7\% versus $2.8 \%, P=0.02)$. Chronic arterial hypertension was reported in $44 \%$ of patients, and in a predefined stratum analysis of these patients, targeting a MAP of 80 to $85 \mathrm{~mm} \mathrm{Hg}$ was associated with better renal function (lower rate of serum creatinine doubling and renal replacement therapy requirements). However, as also reported in one of the observational studies [27], there was no clear relationship between mortality and AKI. Consequently, this finding would suggest that targeting a MAP of 65 to $70 \mathrm{~mm} \mathrm{Hg}$ or 80 to $85 \mathrm{~mm} \mathrm{Hg}$ has similar effects on survival in a heterogeneous population of patients with septic shock. Of note, one limitation of this study [24] was that the actual MAP achieved in the low-target group was $75 \mathrm{~mm} \mathrm{Hg}$ instead of 65 to $70 \mathrm{~mm} \mathrm{Hg}$.

\section{Norepinephrine dosages and levels of mean arterial pressure}

In the comparative studies, the doses of norepinephrine were increased by about $63 \%$ in order to increase MAP from 65 to $85 \mathrm{~mm} \mathrm{Hg}$ [18-24]. Hence, patient management per se may have impacted outcomes in that not only was the level of MAP altered but also the dosages of vasopressors. One of the observational studies analyzed the interactions between MAP, norepinephrine load, and outcome [25]. The norepinephrine load was associated 
with mortality with a relative risk of 1.83 and a $95 \%$ confidence interval of between 1.40 and 2.38. This load was also associated with several disease-related events, and these associations were independent of age, prior history of hypertension, and co-morbidity. This study, therefore, suggests that the norepinephrine load, rather than the MAP per se, was associated with impaired outcomes. This limitation, which is related to the design of these studies, makes it difficult to differentiate between the effects of blood pressure and those of norepinephrine.

\section{Clinical implications}

MAP may be a relevant goal for improving outcomes in septic shock but, although in general a low-MAP target strategy seems to be similar to a high-target strategy in terms of outcomes [24], a single fixed value is not suitable for all patients. The optimal blood pressure target likely ranges from 65 to $85 \mathrm{~mm} \mathrm{Hg}$ and probably lies between 65 and $75 \mathrm{~mm} \mathrm{Hg}$ in most patients. High MAP targets are associated with adverse effects, including atrial fibrillation, probably due to high doses of vasopressors. In patients with chronic hypertension, a level closer to $85 \mathrm{~mm} \mathrm{Hg}$ may be associated with less renal impairment [24]. In support of these observations, in their study of early goal-directed therapy, 6 hours after starting resuscitation, Rivers and colleagues [28] found that the MAPs were $95 \mathrm{~mm} \mathrm{Hg}$ in the early-goal directed therapy group and $81 \mathrm{~mm} \mathrm{Hg}$ in the control group. In this study, around $66 \%$ of the patients had chronic hypertension. As survival was increased in the early-goal directed therapy group, these findings support the targeting of a higher MAP in patients with chronic hypertension [28]. However, this finding was not confirmed in recent studies $[29,30]$. Finally, the 'optimal' MAP differs between patients and within the same patient over time. Hence, there is a need for repeated examination to confirm the adequacy of organ function at the chosen MAP.

A 1-day audit of intensive care practice showed that a MAP goal was pre-fixed in only $70 \%$ of patients with septic shock [31]. In most patients, physicians seem to target a MAP of greater than $65 \mathrm{~mm} \mathrm{Hg}$. However, there is still considerable uncertainty about the relationship between fluid resuscitation, vasopressors, and the timing of these hemodynamic interventions. An interesting retrospective study by Waechter and colleagues [32] assessed the interactions between the three variables. This study suggested that the focus during the first hour of resuscitation be aggressive fluid administration. The timing of vasopressor agents was also important, with the lowest mortality rates associated with starting vasoactive agents 1 to 6 hours after hypotension onset. The duration of hypotension (defined as a MAP of less than $60 \mathrm{~mm} \mathrm{Hg}$ ) was an important predictor of mortality [32]. Hypotension should, therefore, be corrected in all patients without delay.

Central venous pressure (CVP) is often inaccurate for predicting the need for volume expansion [33-35]. However, it represents the downstream pressure, whereas the perfusion pressure determinants are upstream and downstream pressures (Figure 2). The increase in downstream pressure generates congestion [36]. Thus, the optimal MAP most likely also depends on the CVP level. However, CVP does not always reflect the downstream pressure, because of the presence of Starling resistor phenomena in some vascular beds. The Surviving Sepsis Campaign recommends reaching a MAP of at least $65 \mathrm{~mm} \mathrm{Hg}$ and at the same time a CVP of at least $12 \mathrm{~mm} \mathrm{Hg}$ (in mechanically ventilated patients) [3]. However, in terms of organ perfusion, the optimal difference between MAP and CVP remains unclear.

It has been suggested that the microcirculation could be a critical end-point for resuscitation of septic shock. Microcirculatory assessment has been facilitated by the development of non-invasive devices, such as SDF imaging or near-infrared spectroscopy [37-39]. Several observational studies have shown that the microcirculation is markedly altered in patients with septic shock $[12,13,40]$ and that patients with persisting microcirculatory impairment have poorer outcomes than other patients [17,40,41]. An improvement in the microcirculation is associated with increased survival [41], but it is not yet known whether improving microcirculatory blood flow by a pharmacologic intervention can improve outcome from septic shock. Increasing MAP had variable effects on the microcirculation in the four studies that reported this parameter [20-23]. Whether these discrepancies are related to the tool used or to patient differences or the site of measurement or to a combination of these remains unknown. Further studies are required to assess the relevance of these measurements and the type of intervention (that is, increase in flow or pressure or both). The ultimate and definitive end-point would be to demonstrate a relationship between change in microcirculatory blood flow and improvement in organ function and, at best, survival.

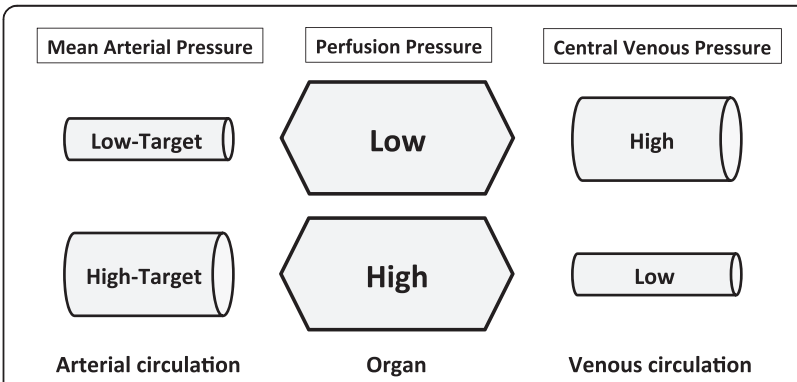

Figure 2 Interactions between mean arterial pressure, central venous pressure, and perfusion pressure. 


\section{Conclusions}

The results of the SEPSISPAM (Sepsis and Mean Arterial Pressure) study [24] suggest that a MAP target of 65 to $75 \mathrm{~mm} \mathrm{Hg}$ is usually sufficient in patients with septic shock, but a higher MAP (around 75 to $85 \mathrm{~mm} \mathrm{Hg}$ ) may be preferable in patients with chronic arterial hypertension. This issue is of major clinical importance in view of the high prevalence of chronic hypertension in patients admitted to intensive care units with septic shock and of the high morbidity associated with AKI. Recent guidelines recommend initially targeting a MAP level of more than $65 \mathrm{~mm} \mathrm{Hg}$ and a higher MAP in septic patients with a history of hypertension who respond to a higher blood pressure [42].

Our results encourage the development of monitoring at the bedside to help determine the optimal level for each individual, although whether an individual-based approach will result in better outcomes than a protocolbased approach targeting a pre-determined level of MAP in all patients remains to be demonstrated [30]. Importantly, the delay to achieve the target is probably as important as the target itself. Finally, the technique used to increase MAP (amount of fluids, association of vasopressors) needs further investigation, in particular in patients with chronic arterial hypertension.

\section{Key messages}

- In heterogeneous populations of patients with septic shock, there is no difference in survival rates for target mean arterial pressure levels of between 65 and $85 \mathrm{~mm} \mathrm{Hg}$.

- In patients with a history of arterial hypertension, a mean arterial pressure level of greater than $75 \mathrm{~mm}$ $\mathrm{Hg}$ may protect against progression to acute kidney injury.

\section{Abbreviations}

AKI: Acute kidney injury; CVP: Central venous pressure; MAP: Mean arterial pressure; SDF: Sidestream darkfield.

\section{Competing interests}

ML and PA served as consultants for LFB (Courtaboeuf, France). PR, JLV, and CM declare that they have no competing interests.

\section{Authors' contributions}

$M L$ drafted the manuscript. PA, PR, JLV, and CM reviewed, discussed, and revised the manuscript for important intellectual content. All authors read and approved the final manuscript.

\section{Author details}

'Service d'Anesthésie et de Réanimation, Chemin des Bourrely, Hôpital Nord, Assistance Publique-Hôpitaux de Marseille, Aix Marseille Université, 13015 Marseille, France. ${ }^{2}$ Département de Réanimation Médicale et de Médecine Hyperbare Centre Hospitalier Universitaire Angers; and Laboratoire de Biologie Neurovasculaire et Mitochondriale Intégrée, CNRS UMR 6214 INSERM U1083, Université Angers, PRES L'UNAM, 4 Rue Larrey, 49100 Angers, France. ${ }^{3}$ Institut für Anästhesiologische Pathophysiologie und Verfahrensentwicklung, Universitätsklinikum, Albert-Einstein-Allee 23, 89081
Ulm, Germany. ${ }^{4}$ Department of Intensive Care, Erasme Hospital, Université Libre de Bruxelles, route de Lennik 808, 1070 Brussels, Belgium.

Published online: 10 March 2015

\section{References}

1. Varpula M, Tallgren M, Saukkonen K, Voipio-Pulkki LM, Pettilä V. Hemodynamic variables related to outcome in septic shock. Intensive Care Med. 2005;31:1066-71.

2. Dünser MW, Takala J, Ulmer H, Mayr VD, Luckner G, Jochberger S, et al. Arterial blood pressure during early sepsis and outcome. Intensive Care Med. 2009;35:1225-33.

3. Dellinger RP, Levy MM, Rhodes A, Annane D, Gerlach H, Opal SM, et al. Surviving sepsis campaign: international guidelines for management of severe sepsis and septic shock: 2012. Crit Care Med. 2013;41:580-637.

4. López A, Lorente JA, Steingrub J, Bakker J, McLuckie A, Willatts S, et al. Multiple-center, randomized, placebo-controlled, double-blind study of the nitric oxide synthase inhibitor 546C88: effect on survival in patients with septic shock. Crit Care Med. 2004;32:21-30

5. Hatib F, Jansen JR, Pinsky MR. Peripheral vascular decoupling in porcine endotoxic shock. J Appl Physiol. 1985;111:853-60.

6. Terborg C, Schummer W, Albrecht M, Reinhart K, Weiller C, Röther J. Dysfunction of vasomotor reactivity in severe sepsis and septic shock. Intensive Care Med. 2001;27:1231-4.

7. Albanèse J, Leone M, Garnier F, Bourgoin A, Antonini F, Martin C. Renal effects of norepinephrine in septic and nonseptic patients. Chest. 2004;126:534-9.

8. Strandgaard S, Olesen J, Skinhoj E, Lassen NA. Autoregulation of brain circulation in severe arterial hypertension. Br Med J. 1973;1:507-10.

9. Wolff CB. Normal cardiac output, oxygen delivery and oxygen extraction. Adv Exp Med Biol. 2007:599:169-82.

10. Elbers PW, Ince C. Mechanisms of critical illness - classifying microcirculatory flow abnormalities in distributive shock. Crit Care. 2006;10:221.

11. De Backer D, Orbegozo Cortes D, Donadello K, Vincent JL. Pathophysiology of microcirculatory dysfunction and the pathogenesis of septic shock. Virulence. 2014:5:73-9.

12. Andrades MÉ, Morina A, Spasić S, Spasojević I. Bench-to-bedside review: sepsis - from the redox point of view. Crit Care. 2011;15:230.

13. Leone M, Blidi S, Antonini F, Meyssignac B, Bordon S, Garcin F, et al. Oxygen tissue saturation is lower in nonsurvivors than in survivors after early resuscitation of septic shock. Anesthesiology. 2009;111:366-71.

14. Payen D, Luengo C, Heyer L, Resche-Rigon M, Kerever S, Damoisel C, et al. Is thenar tissue hemoglobin oxygen saturation in septic shock related to macrohemodynamic variables and outcome? Crit Care. 2009;13:S6.

15. Dünser MW, Hasibeder WR. Sympathetic overstimulation during critical illness: adverse effects of adrenergic stress. J Intensive Care Med. 2009:24:293-316.

16. Corrêa TD, Vuda M, Takala J, Djafarzadeh S, Silva E, Jakob SM. Increasing mean arterial blood pressure in sepsis: effects on fluid balance, vasopressor load and renal function. Crit Care. 2013;17:R21.

17. Georger JF, Hamzaoui O, Chaari A, Maizel J, Richard C, Teboul JL. Restoring arterial pressure with norepinephrine improves muscle tissue oxygenation assessed by near-infrared spectroscopy in severely hypotensive septic patients. Intensive Care Med. 2010;36:1882-9.

18. LeDoux D, Astiz ME, Carpati CM, Rackow EC. Effects of perfusion pressure on tissue perfusion in septic shock. Crit Care Med. 2000;28:2729-32.

19. Bourgoin A, Leone M, Delmas A, Garnier F, Albanèse J, Martin C. Increasing mean arterial pressure in patients with septic shock: effects on oxygen variables and renal function. Crit Care Med. 2005;33:780-6.

20. Deruddre S, Cheisson G, Mazoit JX, Vicaut E, Benhamou D, Duranteau J. Renal arterial resistance in septic shock: effects of increasing mean arterial pressure with norepinephrine on the renal resistive index assessed with Doppler ultrasonography. Intensive Care Med. 2007;33:1557-62.

21. Jhanji S, Stirling S, Patel N, Hinds CJ, Pearse RM. The effect of increasing doses of norepinephrine on tissue oxygenation and microvascular flow in patients with septic shock. Crit Care Med. 2009;37:1961-6.

22. Thooft A, Favory R, Salgado DR, Taccone FS, Donadello K, De Backer D, et al. Effects of changes in arterial pressure on organ perfusion during septic shock. Crit Care. 2011;15:R222. 
23. Dubin A, Pozo MO, Casabella CA, Pálizas Jr F, Murias G, Moseinco MC, et al. Increasing arterial blood pressure with norepinephrine does not improve microcirculatory blood flow: a prospective study. Crit Care. 2009;13:R92.

24. Asfar P, Meziani F, Hamel JF, Grelon F, Megarbane B, Anguel N, et al. High versus low blood-pressure target in patients with septic shock. N Engl J Med. 2014;370:1583-93.

25. Dünser MW, Ruokonen E, Pettilä V, Ulmer H, Torgersen C, Schmittinger CA, et al. Association of arterial blood pressure and vasopressor load with septic shock mortality: a post hoc analysis of a multicenter trial. Crit Care. 2009;13:R181.

26. Badin J, Boulain T, Ehrmann S, Skarzynski M, Bretagnol A, Buret J, et al. Relation between mean arterial pressure and renal function in the early phase of shock: a prospective, explorative cohort study. Crit Care. 2011;15:R135.

27. Poukkanen M, Wilkman E, Vaara ST, Pettilä V, Kaukonen KM, Korhonen AM, et al. Hemodynamic variables and progression of acute kidney injury in critically ill patients with severe sepsis: data from the prospective observational FINNAKI study. Crit Care. 2013;17:R295.

28. Rivers E, Nguyen B, Havstad S, Ressler J, Muzzin A, Knoblich B, et al. Early goal-directed therapy in the treatment of severe sepsis and septic shock. N Engl J Med. 2001;345:1368-77.

29. ARISE Investigators; ANZICS Clinical Trials Group, Peake SL, Delaney A, Bailey M, Bellomo R, Cameron PA, et al. Goal-directed resuscitation for patients with early septic shock. N Engl J Med. 2014;371:1496-506.

30. Investigators PCESS, Yealy DM, Kellum JA, Huang DT, Barnato AE, Weissfeld $L A$, et al. A randomized trial of protocol-based care for early septic shock. N Engl J Med. 2014;370:1683-93.

31. Leone M, Ragonnet B, Alonso S, Allaouchiche B, Constantin JM, Jaber S, et al. Variable compliance with clinical practice guidelines identified in a 1-day audit at 66 French adult intensive care units. Crit Care Med. 2012:40:3189-95.

32. Waechter J, Kumar A, Lapinsky SE, Marshall J, Dodek P, Arabi Y, et al. Interaction between fluids and vasoactive agents on mortality in septic shock: a multicentre, observational study. Crit Care Med. 2014;42:2158-68.

33. Pinsky MR, Payen D. Functional hemodynamic monitoring. Crit Care. 2005;9:566-72

34. Pinsky MR, Teboul JL. Assessment of indices of preload and volume responsiveness. Curr Opin Crit Care. 2005;11:235-9.

35. Michard F, Teboul JL. Using heart-lung interactions to assess fluid responsiveness during mechanical ventilation. Crit Care. 2000;4:282-9.

36. Taylor AE, Moore TM. Capillary fluid exchange. Am J Physiol. 1999;277:\$203-10.

37. Donati A, Tibboel D, Ince C. Towards integrative physiological monitoring of the critically ill: from cardiovascular to microcirculatory and cellular function monitoring at the bedside. Crit Care. 2013;17:S5.

38. Ekbal NJ, Dyson A, Black C, Singer M. Monitoring tissue perfusion, oxygenation, and metabolism in critically ill patients. Chest. 2013;143:1799-808.

39. De Backer D, Ospina-Tascon G, Salgado D, Favory R, Creteur J, Vincent JL. Monitoring the microcirculation in the critically ill patient: current methods and future approaches. Intensive Care Med. 2010;36:1813-25.

40. Sakr Y, Dubois MJ, De Backer D, Creteur J, Vincent JL. Persistent microcirculatory alterations are associated with organ failure and death in patients with septic shock. Crit Care Med. 2004;32:1825-31.

41. Trzeciak S, McCoy JV, Phillip Dellinger R, Arnold RC, Rizzuto M, Abate NL, et al. Early increases in microcirculatory perfusion during protocol-directed resuscitation are associated with reduced multi-organ failure at $24 \mathrm{~h}$ in patients with sepsis. Intensive Care Med. 2008;34:2210-7.

42. Cecconi M, De Backer D, Antonelli M, Beale R, Bakker J, Hofer C, et al. Consensus on circulatory shock and hemodynamic monitoring. Task force of the European Society of Intensive Care Medicine. Intensive Care Med. 2014:40:1795-815 